\title{
EVALUASI PRDSES PEMBELAJARAN DENGAN JENIS DISCDVERY BASED LEARNING PADA MATA KLLIAH KAJIAN MUSIK 2 DI PS. SENI MUSIK FBS UHN MEDAN
}

\author{
Ance Juliet Panggabean \\ Fakultas Bahasa Dan Seni Universitas HKBP Nammensen Medan \\ ance.panggabean国uhn.ac.id
}

\begin{abstract}
Info Artikel
Diterima : 13 Januari 2020

Revisi : : I6 Februari 2020

Terbit : :20 Juni 2020

\section{Key words:}

Learning Model, Discavery

Based Learning, Study, Music
\end{abstract}

\section{Kata Kunci: \\ Model Pembelajaran, Discavery \\ Based Learning, Kajian Musik}

\section{Corresponding Author :}

Ance Juliet Panggabean, E-mail : ance.panggabean回uhn.ac.id

\section{Abstract}

Music Study Course 2 (Two) is one of the subjects with the main competence in interest / concentration in Musicology and History. The problem in this research is how the influence of the application of discovery based learning models in music study subjects and how the results of student creativity after using discavery based learning learning madels. Through this discovery learning model learning is one of the teaching models where the lecturer does not directly give the final results or conclusions from the material he delivered, but students are given the opportunity to find and find that creativity, so that this learning process will be remembered by students of all time and the results obtained is not easily forgatten.

Abstrak

Kajian Musik 2 (Dua) adalah salah satu mata kuliah dengan kompetensi utama pada minat/konsentrasi Musikologi dan Sejarah. Permasalahan penelitian ini adalah bagaimana pengaruh penerapan madel pembelajaran discavery based learning pada mata kuliah Kajian Musik II (dua) dan bagaimana hasil kreatifitas mahasiswa setelah menggunakan model pembelajaran discavery based learning. Melalui model pembelajaran discavery based learning ini merupakan salah satu model mengajar dimana dosen tidak langsung memberi hasil akhir atau kesimpulan dari materi yang disampaikannya, melainkan peserta didik diberi kesempatan mencari dan menemukan kreativitas tersebut, sehingga proses pembelajaran ini yang akan diingat oleh peserta didik sepanjang masa serta hasil yang didapat tidak mudah dilupakan. 


\section{PENDAHULUAN}

Mata kuliah Kajian Musik 2 adalah salah satu mata kuliah dengan kompetensi utama pada minat/knnsentrasi Musikologi dan Sejarah dengan kelompok MKK kode mata kuliah GM 124136 di Program Studi Seni Musik Fakultas Bahasa dan Seni UHN Medan. Pada sebaran mata kuliah di PS. Seni Musik mata kuliah Kajian Musik 2 ini disebar pada semester lima (V). Adapun deskripsi mata kuliah Kajian Musik 2 ini adalah mengkaji dan menguraikan tentang sejarah keberadaan musik Modern dan perkembangannya di dunia dan di Indanesia, termasuk beberapa kamposer yang berkecimpung didalamnya dan literatur kekaryaannya. Jumlah mahasiswa 20 orang. Mata kuliah ini merupakan mata kuliah yang memotivasi, membantu, mengarahkan, serta membimbing mahasiswa untuk kreatif dalam berkarya musik. Mata kuliah Kajian Musik 2 merupakan mata kuliah yang menuntut mahasiswa untuk lebih berkreasi dan inovatif. Namun, berdasarkan pengamatan peneliti sekaligus merupakan dasen yang mengampu mata kuliah ini mahasiswa yang turut serta pada mata kuliah Kajian Musik 2 TA. 2018/2019 ini tampak kurang aktif dalam mengikuti perkuliahan. Penggunaan model ceramah dan diskusi dirasakan masih kurang dalam mengatasi persaalan pada proses pembelajaran. Berdasarkan analisis peneliti sekaligus sebagai dasen pengampu pada mata kuliah tersebut, maka peneliti tertantang dan termativasi untuk menerapkan penggunaan model pembelajaran discavery based learning pada mata kuliah Kajian Musik 2 tersebut. Tujuannya adalah agar mahasiswa dapat lebih termativasi dalam berkreatifitas didalam kelas dan diluar kelas.

Model pembelajaran discaverylearning merupakan salah satu mengajar dimana guru tidak langsung memberi hasil akhir atau kesimpulan dari materi yang disampaikannya, melainkan peserta didik diberi kesempatan mencari dan menemukan kreativitas tersebut, sehingga proses pembelajaran ini yang akan diingat oleh peserta didik sepanjang masa serta hasil yang didapat tidak mudah dilupakan (Hosnan, 2014: 280-28Z).

Pengertian Proses belajar mengajar merupakan suatuproses yang mengandung serangkaian perbuatan guru dan siswa atas dasar hubungan timbal balik yang berlangsung dalam situasi edukatif untuk mencapai tujuan tertentu. Menurut Demar Hamalik ( 2015 : 36 ) belajar adalah modifikasi atau memperteguh kelakuan melalui pengalaman. (learning is defined as the madification or streng thening of behaviar through experiencin).

Menurut Kamus Besar Bahasa Indanesia evaluasi adalah penilaian. Pengertian Evaluasi Pembelajaran diambil dari bahasa Inggris yang yakni Evaluation. Pada dasarnya, pengertian evaluasi adalah suatu kegiatan untuk memberikan nilai atau pertimbangkan sesuai dengan kriteria yang ada untuk mendapatkan hasil evaluasi yang objektif dan meyakinkan. Kriteria yang digunakan bisa diperuleh dari informasi kualitatif dan kuantitatif. Dalam kegiatan pengajaran, evaluasi pembelajaran dijelaskan oleh banyak ahli di bidangnya.Evaluasi merupakan saduran dari bahasa Inggris "evaluatior" yang diartikan sebagai penaksiran atau penilaian. Nurkancana (I983) menyatakan bahwa evaluasi adalah kegiatan yang dilakukan berkenaan dengan proses untuk menentukan nilai dari suatu hal.

Dalam Permen №. 41 tahun 2007 tentang Standar proses dinyatakan bahwa evaluasi proses pembelajaran dilakukan untuk menentukan kualitas pembelajaran secara keseluruhan, mencakup tahap perencanaan poses pembelajaran, pelaksanaan proses pembelajaran, dan penilaian hasil pembelajaran. Evaluasi proses pembelajaran diselenggarakan dengan cara:

a. Membandingkan poses pembelajaran yang dilaksanakan guru dengan standar proses.

b. Mengidentifikasi kinerja guru dalam proses pembelajaran sesuai dengan kampetensi guru. 
Menurut undang-Undang Sistem Pendidikan Nasional No. 20 Tahun 2003 menyatakan pembelajaran adalah "proses interaksi peserta didik dengan pendidik dan sumber belajar pada suatu lingkungan belajar". Pembelajaran sebagai proses belajar yang dibangun oleh guru untuk mengembangkan kreatifitas berpikir yang dapat meningkatkan kemampuan berpikir siswa, serta dapat meningkatkan kemampuan mengkantruksikan pengetahuan baru sebagai upaya meningkatkan penguasaan yang baik terhadap materi pelajaran.

\section{Rumusan Masalah}

I. Bagaimana Pengaruh Penerapan Model Pembelajaran Discavery Based Learning Pada Mata Kuliah Kajian Musik 2?

2. Bagaimana Hasil Kreatifitas Mahasiswa Setelah Menggunakan Model Pembelajaran Discavery Based Learning?

\section{Tujuan Penelitian}

Berdasarkan rumusan masalah di atas, secara umum penelitian ini bertujuan untuk meneliti Pengaruh Penerapan Model Pembelajaran Discovery Based Learning Pada Mata Kuliah Kajian Musik 2.

1. Untuk mengetahui bagaimana Pengaruh Penerapan Model Pembelajaran Discavery Based Learning dalam proses pembelajaran pada mata kuliah Kajian Musik Z.

2. Untuk mengetahui bagaimana hasil kreatifitas setelah penerapan madel pembelajaran Discavery Based Learningpada mata kuliah Kajian Musik 2.

\section{Manfaat Penelitian}

Hasil penelitian ini diharapkan dapat memberikan kantribusi/manfaat secara tearitis maupun praktis:

I. Secara Teoritis:

Hasil penelitian ini diharapkan dapat memberikan wawasan dan pengetahuan tentang evaluasi proses pembelajaran dengan jenis Discavery Based Learning pada mata kuliah Kajian Musik 2 di PS. Seni Musik FBS UHN Medan.

2. Secara Praktis:

a. Bagi dosen dalam mengajarkan pembelajaran Kajian Musik 2 dapat menggunakan model pembelajaran discavery based learning yang lebih baik dan lebih variatif untuk mencapai hasil yang lebih baik.

b. Bagi Pragram Studi Seni Musik FBS UHN Medan, dapat memberikan kantribusi bagi kepustakaan yang diharapkan dapat menjadi referensi dalam mengembangkan madel pembelajaran discovery based learning yang lebih bervariasi dan dapat menambah wawasan keilmuan dalam bidang Seni Musik.

\section{TINJALAN PUSTAKA}

Nurkancana (1983) menyatakan bahwaevaluasi adalah kegiatan yang dilakukan berkenaan dengan proses untuk menentukan nilai dari suatu hal. Dalam Permen No. 41 tahun 2007 tentang Standar proses dinyatakan bahwa evaluasi proses pembelajaran dilakukan untuk menentukan kualitas pembelajaran secara keseluruhan, mencakup tahap perencanaan poses pembelajaran, pelaksanaan proses pembelajaran, dan penilaian hasil pembelajaran. Evaluasi proses pembelajaran diselenggarakan dengan cara: 
a. Membandingkan poses pembelajaran yang dilaksanakan guru dengan standar proses.

b. Mengidentifikasi kinerja guru dalam proses pembelajaran sesuai dengan kampetensi guru

Menurut undang-Undang Sistem Pendidikan Nasional No. 20 Tahun 2003 menyatakan pembelajaran adalah "proses interaksi peserta didik dengan pendidik dan sumber belajar pada suatu lingkungan belajar". Pembelajaran sebagai proses belajar yang dibangun oleh guru untuk mengembangkan kreatifitas berpikir yang dapat meningkatkan kemampuan berpikir siswa, serta dapat meningkatkan kemampuan mengkantruksikan pengetahuan baru sebagai upaya meningkatkan penguasaan yang baik terhadap materi pelajaran.

Menurut Mustikasari, Ardiani S. Si, M. Pd, (2010) dalam evaluasi proses pembelajaran, yang perlu diperhatikan juga adalah mendokumentasikan berbagai hal yang menyangkut proses pembelajaran. Hal-hal yang perlu didakumentasikan adalah:

I. RPS dan Silabus .

2. Dokumen hasil diskusi, laparan atau makalah/essay, laporan hasil analis terhadap suatu masalah yang menunjukkan keterlibatan siswa dalam kegiatan belajar mengajar.

3. Dokumen pemanfaatan berbagai fasilitas yang menunjukkan difungsikannya sumber-sumber belajar

4. Dokumen penugasan latihan ketrampilan membuat melodi, seperti: hasil karya cipta musik, pertunjukan kecil-kecilan di dalam kelas berupa foto atau video mahasiswa.

Hamalik, Demar (2015). Proses Belajar Mengajar, yaitu konsep pengajaran dan kurikulum, komponenkomponen pengajaran, implementasi pengajaran, dan strategi pengajaran yang berpusat pada siswa.

\section{METODOLOGI PENELITIAN}

\section{Metode Dasar}

Metode dasar yang akan diterapkan di dalam penelitian ini adalah metode deskriptif. Dengan kata lain, penelitian ini dimaksudkan untuk membuat deskripsi atau gambaran secara lengkap, faktual dan teliti mengenai fakta-fakta, sifat serta hubungan antara fenomena yang diselidiki. Selanjutnya, metade ini akan mendasari penelitian ini khususnya di dalam hal pengumpulan data maupun penganalisaan data.

\section{Metade Pengumpulan Data}

Ada beberapa metode yang diterapkan di dalam pengumpulan data, yaitu:

(I) Metade Observasi, (Z) Metade Kepustakaan. Melalui metade kepustakaan diharapkan dapat memperoleh datadata tertulis tentang evaluasi proses pembelajaran dengan jenis Discavery Based Learning pada mata kuliah Kajian Musik 2 di PS. Seni Musik FBS UHN Medan. Sedangkan, metade observasi dimungkinkan untuk dapat membandingkan apa yang disebutkan infarman serta apa yang dilakukan infarman. Data juga dikumpulkan dengan cara merekam kegiatan evaluasi proses pembelajaran dengan jenis Discovery Based Learning pada mata kuliah Kajian Musik 2 di PS. Seni Musik FBS UHN Medan dengan menggunakan perangkat perekam audio-visual.

\section{Metode Analisis}

Prosedur analisis data akan dilakukan sebagai berikut:

a. Seleksi Data 
Seleksi data dilakukan dalam rangka memilih dan merangkum data sesuai dengan kebutuhan penelitian tentang evaluasi proses pembelajaran dengan jenis Discovery Based Learning pada mata kuliah Kajian Musik 2 di PS. Seni Musik FBS UHN Medan.

b. Klasifikasi Data

Pengklasifikasian data dilakukan untuk menyusun data dasar kriteria dan pembagian tertentu.

c. Deskripsi Data

Pada langkah ini, data diuraikan dengan sebaik-baiknya sehingga diperoleh gambaran yang jelas dan terperinci tentang data khususnya yang relevan terhadap substansi penelitian.

d. Interpretasi

Data interpretasi berusaha mencari hubungan antara fakta-fakta yang ditemukan dan memberikan pemahaman yang jelas mengenai evaluasi proses pembelajaran dengan jenis Discavery Based Learning pada mata kuliah Kajian Musik 2 di PS. Seni Musik FBS UHN Medan.

e. Menarik Kesimpulan

Langkah akhir adalah menarik kesimpulan, yaitu menegaskan kembali secara ringkas dan padat apa yang ditemukan dari pembahasan-pembahasan sebelumnya.

\section{HASIL DAN PEMBAHASAN}

Model pembelajaran discaverylearning merupakan salah satu madel mengajar dimana guru tidak langsung memberi hasil akhir atau kesimpulan dari materi yang disampaikannya, melainkan peserta didik diberi kesempatan mencari dan menemukan kreativitas tersebut, sehingga proses pembelajaran ini yang akan diingat oleh peserta didik sepanjang masa serta hasil yang didapat tidak mudah dilupakan (Hosnan, 2014: 280-282). Mata kuliah Kajian Musik 2 ini adalah mata kuliah yang mengkaji dan menguraikan tentang sejarah keberadaan musik Modern dan perkembangannya di dunia dan di Indanesia, termasuk beberapa kampaser yang berkecimpung didalamnya dan literatur kekaryaannya. Mahasiswa dituntun untuk peka terhadap sejarah keberadaan musik Modern dan perkembangannya.

Pada pembelajaran mata kuliah Kajian Musik 2 yang menggunakan pendekatan scientific, instrumen penilaian harus dapat menilai keterampilan berpikir tingkat tinggi (HDTS, "HigherDrder thinking Skill") menguji proses analisis, sintesis, evaluasi bahkan sampai kreatif. Untuk menguji keterampilan berpikir mahasiswa, untuk menilai hasil belajar pada mata kuliah Kajian Musik 2 ujian tengah semester maupun ujian akhir semester dalam menjawab saal-saal melalui proses berpikir yang sesuai dengan kata kerja operasional dalam Taksonomi Bloum. Penggunaan Discavery Learning, ingin merubah kondisi belajar yang pasif menjadi aktif dan kreatif. Mengubah pembelajaran yang teacher ariented ke student ariented. Merubah modus Ekspository peserta didik hanya menerima infarmasi secara keseluruhan dari guru ke madus Discavery peserta didik menemukan infarmasi sendiri.

Dalam Discavery Learning bahan ajar tidak disajikan dalam bentuk akhir, peserta didik dituntut untuk melakukan berbagai kegiatan menghimpun informasi, membandingkan, mengkategorikan, menganalisis, mengintegrasikan, mereorganisasikan bahan serta membuat kesimpulan- kesimpulan.Bruner mengatakan bahwa proses belajar akan berjalan dengan baik dan kreatif jika guru memberikan kesempatan kepada peserta didik untuk menemukan suatu konsep, teori, aturan, atau pemahaman melalui contoh-contoh yang ia jumpai dalam kehidupannya (Budiningsih, 2005:41).

Langkah-langkah dalam mengaplikasikan model discavery learning di kelas adalah sebagai berikut:

Evaluasi Proses Pembelajaran Dengan Jenis Discavery Based Learning Pada Mata Kuliah Kajian Musik 2 Di PS Seni Musik FBS UHN Medan 


\section{Perencanaan}

Perencanaan pada model ini meliputi hal-hal sebagai berikut.

a. Menentukan tujuan pembelajaran

b. Melakukan identifikasi karakteristik peserta didik (kemampuan awal, minat,gaya belajar, dan sebagainya)

c. Memilih materi pelajaran

d. Menentukan topik-topik yang harus dipelajari peserta didik secara induktif (dari contoh- contoh generalisasi)

e. Mengembangkan bahan-bahan belajar yang berupa contoh-contoh,ilustrasi, tugas dan sebagainya untuk dipelajari peserta didik

f. Mengatur topik-topik pelajaran dari yang sederhana ke kompleks, dari yang konkret ke abstrak, atau dari tahap enaktif, iknnik sampai kesimbolik

g. Melakukan penilaian proses dan hasil belajar peserta didik

\section{Pelaksanaan}

Menurut Syah (2004) dalam mengaplikasikan metode Discavery Learning di kelas, ada beberapa prosedur yang harus dilaksanakan dalam kegiatan belajar mengajar secara umum sebagai berikut.

a. Stimulation(stimulasi/pemberian rangsangan)

Pertama-tama pada tahap ini pelajar dihadapkan pada sesuatu yang menimbulkan kebingungannya dan timbul keinginan untuk menyelidiki sendiri. Guru dapat memulai kegiatan pembelajaran dengan mengajukan pertanyaan, anjuran membaca buku, dan aktivitas belajar lainnya yang mengarah pada persiapan pemecahan masalah. Stimulasi pada tahap ini berfungsi untuk menyediakan kondisi interaksi belajar yang dapat mengembangkan dan membantu peserta didik dalam mengeksplorasi bahan.Dengan demikian searang Guru harus menguasai teknik-teknik dalam memberi stimulus kepada peserta didik agar tujuan mengaktifkan peserta didik untuk mengeksplorasi dapat tercapai.

b. Prablem statement (pernyataan/ identifikasi masalah)

Setelah dilakukan stimulation guru member kesempatan kepada peserta didik untuk mengidentifikasi sebanyak mungkin masalah yang relevan dengan bahan pelajaran, kemudian salah satunya dipilih dan dirumuskan dalam bentuk hipatesis (jawaban sementara atas pertanyaan masalah)

c. Data callection (pengumpulan data)

Pada saat peserta didik melakukan eksperimen atau eksplorasi, guru member kesempatan kepada para peserta didik untuk mengumpulkan infarmasi sebanyak-banyaknya yang relevan untuk membuktikan benar atau tidaknya hipotesis. Data dapat diperaleh melalui membaca literatur, mengamati objek, wawancara dengan narasumber, melakukan uji coba sendiri dan sebagainya.

d. Data pracessing (pengulahan data) 
Menurut Syah (2004:244) pengolahan data merupakan kegiatan mengolah data dan informasi yang telah diperuleh para peserta didik baik melalui wawancara, observasi, dan sebagainya, lalu ditafsirkan.

e. Verification (pembuktian)

Pada tahap ini peserta didik melakukan pemeriksaan secara cermat untuk membuktikan benar atau tidaknya hipotesis yang telah ditetapkan, dihubungkan dengan hasil data processing. Berdasarkan hasil pengolahan dan tafsiran, atau informasi yang ada, pernyataan atau hipotesis yang telah dirumuskan terdahulu itu kemudian dicek, apakah terjawab atau tidak, apakah terbukti atau tidak.

f. Generalization(menarik kesimpulan/generalisasi)

Tahap generalisasi/menarik kesimpulan adalah proses menarik sebuah kesimpulan yang dapat dijadikan prinsip umum dan berlaku untuk semua kejadian atau masalah yang samadengan memperhatikan hasil verifikasi. Berdasarkan hasil verifikasi maka dirumuskan prinsip- prinsip yang mendasari generalisasi.

3. Sistem Penilaian

Dalam Model Pembelajaran Discavery, penilaian dapat dilakukan dengan menggunakan tes maupun nan tes. Penilaian dapat berupa penilaian pengetahuan, keterampilan, sikap, atau penilaian hasil kerja peserta didik. Jika bentuk penialainnya berupa penilaian pengetahuan, maka dalam model pembelajaran discavery dapat menggunakan tes tertulis. Jika bentuk penilaiannya menggunakan penilaian proses, sikap, atau penilaian hasil kerja peserta didik, maka pelaksanaan penilaian dapat menggunakan contohcontoh format penilaian sikap seperti yang ada pada uraian penilaian proses dan hasil belajar pada materi berikutnya.

\section{Analisis Pendekatan Saintifik Pada Model Pembelajaran}

\begin{tabular}{|c|c|}
\hline Topik & Lagu Papuler/Madern \\
\hline Sub Topik & Aransemen lagu sigulempang \\
\hline Kompetensi Dasar & $\begin{array}{l}\text { 3.2 Menganalisis musik kreasi berdasarkan makna, simbol, dan nilai } \\
\text { estetis } \\
\text { 4.2 Menampilkan musik kreasi dengan membaca partitur lagu }\end{array}$ \\
\hline $\begin{array}{l}\text { Indikator } \\
\text { Pencapaian } \\
\text { Kompetensi }\end{array}$ & $\begin{array}{ll}\text { - } & \text { Menjelaskan fungsiaransemen } \\
\text { - } & \text { Menulis notasi masing-masing alat musik ke dalam partiturlagu }\end{array}$ \\
\hline $\begin{array}{l}\text { Model } \\
\text { Pembelajaran }\end{array}$ & Discavery Learning \\
\hline Alokasi Waktu & Ix pertemuan ( 2 JP) \\
\hline
\end{tabular}

\begin{tabular}{|c|c|c|c|c|c|}
\hline \multirow{2}{*}{$\begin{array}{l}\text { SINTAKSIS } \\
\text { MODEL }\end{array}$} & \multicolumn{5}{|c|}{ PENDEKATAN SAINTIFIK } \\
\hline & Mengamati & Menanya & $\begin{array}{l}\text { Mengumpulkan } \\
\text { Informasi }\end{array}$ & Mengasosiasi & $\begin{array}{l}\text { Mengkomu } \\
\text { nikasikan }\end{array}$ \\
\hline
\end{tabular}

Evaluasi Proses Pembelajaran Dengan Jenis Discavery Based Learning Pada Mata Kuliah Kajian Musik 2 Di PS 


\begin{tabular}{|c|c|c|c|c|}
\hline $\begin{array}{l}\text { I.Stimulation } \\
\text { (stimullasi } \\
\text { Pemberian } \\
\text { rangsangan) }\end{array}$ & $\begin{array}{l}\text { Pemberian } \\
\text { stimulus dengan } \\
\text { menyajian } \\
\text { contah lagu yang } \\
\text { diaransemen } \\
\text { ulang }\end{array}$ & & & \\
\hline $\begin{array}{l}\text { 2. Prablem } \\
\text { statemen } \\
\text { (pertanyaan ／ } \\
\text { identifikasi } \\
\text { masalah) }\end{array}$ & 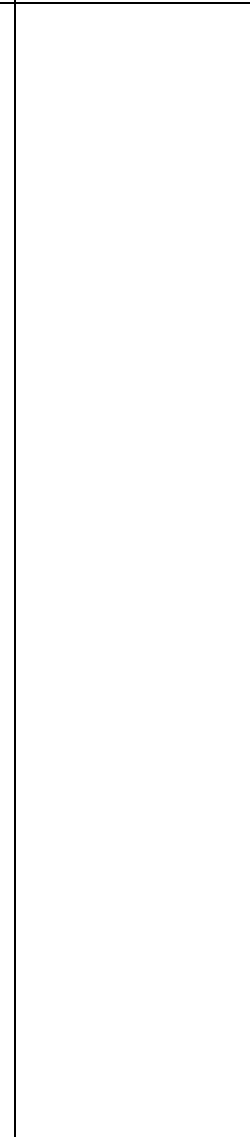 & \begin{tabular}{|ll} 
Guru & memberi \\
kesempatan \\
kepada & peserta \\
didik & untuk \\
bertanya & \\
setelah & mereka \\
mengamati lagu \\
yang disajikan. \\
Contoh \\
pertanyaan yang \\
berkaitan \\
dengan \\
pengamatan \\
pesertadidik \\
Mengapa $\quad$ lagu \\
dibuat \\
dalam \\
aransemen yang
\end{tabular} & & \\
\hline $\begin{array}{l}\text { 3. Data callection } \\
\text { (pengumpulan } \\
\text { data }\end{array}$ & & i & $\begin{array}{l}\text { Mencatat data } \\
\text { hasil } \\
\text { pengamatan } \\
\text { Mencatat } \\
\text { infarmasi } \\
\text { tentang urutan } \\
\text { lagu, } \\
\text { harmonisasi, } \\
\text { dan bentuk lagu }\end{array}$ & \\
\hline $\begin{array}{l}\text { 4.Data processing } \\
\text { (pengulahan } \\
\text { Data) }\end{array}$ & & - & & $\begin{array}{l}\text { Mendiskusikan } \\
\text { hasil } \\
\text { pengamatan }\end{array}$ \\
\hline
\end{tabular}

Evaluasi Prases Pembelajaran Dengan Jenis Discavery Based Learning Pada Mata Kuliah Kajian Musik 2 Di PS 


\begin{tabular}{|c|c|c|c|}
\hline $\begin{array}{l}\text { 5. Verification } \\
\text { (pembuktian) }\end{array}$ & - & \begin{tabular}{|l|}
$\begin{array}{l}\text { Pada tahap } \\
\text { verifikasi }\end{array}$ \\
peserta didik \\
mendiskusika \\
nar hasil \\
pengamatan \\
terhadap lagu \\
yang dibuat \\
aransemen baru
\end{tabular} & \\
\hline $\begin{array}{l}\text { 6. Generalization } \\
\text { (menarik } \\
\text { kesimpulan) }\end{array}$ & - & $\begin{array}{l}\text { Menyimpulkan } \\
\text { bentuk lagu } \\
\text { Menemukan } \\
\text { akar/harmani } \\
\text { sasi baru }\end{array}$ & $\begin{array}{l}\text { Setelah } \\
\text { menemuka } \\
n \\
\text { kesimpula } \\
\text { n, peserta } \\
\text { didik } \\
\text { membuat } \\
\text { laporan } \\
\text { aranseme } \\
\text { n dan } \\
\text { memprese } \\
\text { ntasikan } \\
\text { hasil } \\
\text { aranseme } \\
\text { n. }\end{array}$ \\
\hline
\end{tabular}

Di dalam proses belajar, Bruner mementingkan partis seni budaya siaktif dari tiap peserta didik, dan mengenal dengan baik adanya perbedaan kemampuan. Untuk menunjang proses belajar perlu lingkungan memfasilitasi rasa ingin tahu peserta didik pada tahap eksplarasi. Lingkungan ini dinamakan Discavery Learning Enviranment, yaitu lingkungan dimana peserta didik dapat melakukan eksplarasi, penemuan-penemuan baru yang belum di kenal atau pengertian yang mirip dengan yang sudah diketahui. Lingkungan seperti ini bertujuan agar peserta didik dalam proses belajar dapat berjalan dengan baik dan lebih kreatif.

\section{DAFTAR PUSTAKA}

Budiningsih, C. Asri, 2005, Belajar dan Pembelajaran. Jakarta: Rineka Cipta.

Hosnan, 2014, Pendekatan Saintifik dan Kantekstual dalam Pembelajaran Abad 2I. Bagar. Ghalia Indanesia. Hamalik, Demar, 2015, Kurikulum dan Pembelajaran. Jakarta: Bumi Aksara.

Nurkancana, Wayan, 1983, Evaluasi pendidikan. Label: 371.26 NUR e Penerbit: Surabaya : Usaha Nasional Depdiknas, 2003, Undang-Undang Na.20 Tahun 2003 tentang Sistem Pendidikan Nasional. Jakarta: Depdiknas Permendiknas No. 41 Tahun 2007 tentang Standar Proses Untuk Satuan Pendidikan Dasar dan Menengah

\section{Sumber Internet:}


Ardiani Mustikasari, S. Si, M. Pd, 2010, Evaluasi Proses Pembelajaran diakses tanggal I0 April 2019. (https://gayuhtunggadewi.wordpress.com/kumpulan-artike//evaluasi-prosespembelajaran/)

Ardiani Mustikasari, 20II, Mengena/ Media Pembelajaran, Artikel, diakses tanggal ID April 2019.

Mustikasari Ardiani, 2008, Mengena/ Media Pembelajaran. (http://eduarticles.com/mengenal-mediapembelajaran) diunduh pada tanggal IO Oktober 20I9 pukul 08.40 WIB.

Syah, 2004, Psikalogi Pendidikan dengan Pendekatan Baru. Bandung: PT Remaja Rosdakarya diakses tanggal 08 Oktober 2019 (http://edutaka.blogspot.co.id/2015/03/model-pembelajaran-discoverylearning.html) pada jam 08. 0 (प) wib. 